which is both concise and lucid, and is well illustrated. Then follows a series of chapters dealing with different groups of spinal disease, commencing logically with congenital anomalies.

Also included is a chapter on radiological diagnosis of vertebral lesions, and another which describes the techniques of vertebral biopsy by needle aspiration.

Each chapter maintains a high standard and contains much informative and thought provoking material. The quality of illustrations and X-ray reproduction generally is good, but some of the $\mathrm{X}$-rays lack definition and the detail is too obscure to demonstrate the points referred to in the text. The micro-photographs are very well reproduced. To aid the reader whose appetite has been whetted, each chapter has a short bibliography appended.

Because of the multiple authorship there is considerable variation in the style of writing, and some of the views expressed are personal opinions which may not receive general acceptance. Several of the chapters are absolutely first class, particularly those dealing with vertebral tumours, cervical spondylosis, ankylosing spondylitis, traumatic paraplegia, and osteoporosis.

Tuberculosis of the spine is discussed in five pages, which may be an indication of the relative infrequency of its occurrence these days but may reflect the editors' problem in keeping this book to manageable proportions.

Mechanical disorders of the spine, too, are dealt with rather briefly, and one would have wished for a fuller discussion of this important subject were more space available.

No book on the subject of the spine would be complete without mention of "functional ' backache and Tegner has contributed a short article on this increasing problem. He does not pull his punches and ends on a note of profound pessimism which I fear is well founded.

The editors and individual authors are to be congratulated on producing a most interesting and useful book. It can be read with enjoyment and profit not only by orthopaedic surgeons but can be thoroughly recommended to all who have to deal with natients complaining of 'back trouble.'

\section{MODERN TRENDS IN PATHOLOGY}

Edited by D. H. Collins, M.D., F.R.C.P. Pp. 346 , with 134 illustrations. London: Butterworth \& Co. Ltd. I 959. £3 ros.

The ' modern trends' series of books, published by Butterworths, have established themselves as an invaluable aid to that increasingly difficult task of ' keeping up to date.' In this volume, Professor Collins has interpreted the term 'pathology' in a very wide sense and has in consequence produced an extremely fascinating book. In particular, it is good to see in a book on pathology, a review by Professor Oakley of his work on the localization of antibody production-work which he has carrie f $^{\frac{1}{5}}$ out over a considerable number of years. Equall valuable are reviews by Professor Payling Wrighe on his observations on movements of neurotoxins and neuroviruses in the nervous system; byo Professor Pulvertaft on his well-known tissue. culture work on normal and abnormal tissues and by Professor Gough on occupational diseases? of the lung.

Two papers on carcinogenesis deserve carefuE study because they deal with aspects of this subject not normally considered by pathologists in Europe $\mathbb{\mathbb { }}$ one by Professor J. N. P. Davies on cancer in Africa, which records some of the fascinatings differences between pathological changes seen in $\overrightarrow{0}$ Africa as compared with Europe; the second paper-by Professor Steiner-reviews the complexw problem of cancer of the liver. Although this review covers a wide field, it is in part comples mentary to Professor Davies' paper for it considerş. the reasons for the high incidence of liver cancer in Africans living in Africa or compared with the much lower incidence of those of African descent living in America.

It is an interesting reflection on present-day pathology that in an article, mainly anatomical, on the adrenal cortex Professor Symington has felt compelled to include six pages on the chemistryof steroid hormones although it is doubtful if manyopo his readers will gain much from this introductiof They will, however, learn much from the descrip 3 tions of the anatomical changes in the gland ing different diseases.

Among other subjects covered, there are teresting chapters on 5-hydroxytryptamine, whä body irradiation and the acute inflammatory reaction.

In all this book contains $\mathrm{I}_{5}$ chapters all of which maintain a high standard. They provide a valuable survey of the immense strides made during the lasp few years in the study of body tissues. The editor is to be congratulated. The book is well produce 5 and well illustrated.

\section{CARDIOVASCULAR SOUND IN HEALTF' AND DISEASE}

By. Victor A. McKusick, M.D. Pp. xii + 570 with 494 illustrations: London: Baillière Tindall \& Cox, Ltd. I958. £6.

Dr. McKusick dedicates his monograph on cardiovascular sound to the memory of Williano Harvey and the Father of modern physiolog?. would have been pleased with it. He was wels aware of the "pulse that can be heard within the chest.' Indeed his reference to heart sounds is according to Dr. McKusick the earliest and clearest which survives - no mean compliment in text which lists 1607 references. Everything of interest to the physician relating to cardiovascular sound is herein compiled in an orderly and masterly? fashion. The historical survey, delightfully bal- 